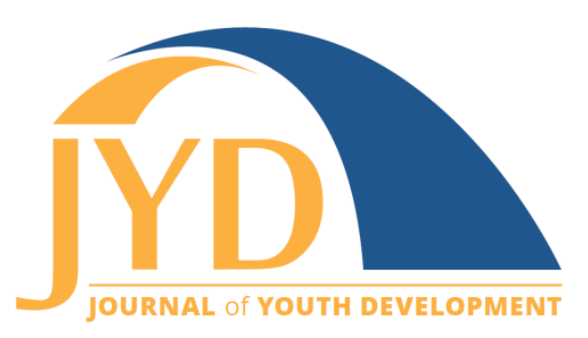

http://jyd.pitt.edu/ | Vol. 15 Issue 1 DOI 10.5195/jyd.2020.812 | ISSN 2325-4017 (online)

\title{
Employee Churn in After-School Care: Manager Influences on Retention and Turnover
}

\author{
Michele Wilkens \\ NAA Board of Directors \\ michelewilkens1@gmail.com
}

\begin{abstract}
This study examined field employee turnover at a national after-school program provider to assess the knowledge, skills, motivation, and organizational influences of those with the greatest impact on employee retention-area managers who oversee after-school programs and their frontline staff. Clark and Estes' (2008) gap analysis served as the general conceptual framework for the study. A convergent parallel mixed methods case study was conducted using historical document analysis, surveys, interviews, and observations. Analysis revealed high employee retention (74\%) as well as high turnover (62\%), which can coexist when most staff are retained, but a smaller segment repeatedly churns over the same period. Specifically, recurring turnover among 37\% of staff roles was found to be the source of the high turnover rate, while $63 \%$ of roles remained filled and stable. Further analysis of managers' mindset illuminated barriers to success with retention, including limited knowledge of factors related to turnover, perception of minimal organizational focus on and resources for retention, significant external locus of control over turnover, and lack of ownership and accountability for turnover. After implementing contextspecific solutions grounded in literature and in the New World Kirkpatrick Model (Kirkpatrick \& Kirkpatrick, 2016), a 1-year follow-up indicated elevations in 16 of 17 areas of manager mindset around retention, including $90 \%$ or higher agreement in 12 of 17 areas, a 22\% decrease in turnover, an $8 \%$ increase in stable roles, and an $11 \%$ decrease in unstable or repeatedly churning roles.
\end{abstract}

Key words: retention, turnover, after-school, gap analysis

\section{Introduction}

\section{Turnover Definition and Precursors}

Across industries, human resource professionals cite employee turnover as their most important challenge (Society for Human Resource Management, 2015). Turnover is defined as employee

\footnotetext{
(c) E EY New articles in this journal are licensed under a Creative Commons Attribution 4.0 License.
} This journal is published by the University Library System, University of Pittsburgh and is cosponsored by the University of Pittsburgh Press. The Journal of Youth Development is the official peer-reviewed publication of the National Association of Extension 4-H Youth Development Professionals and the National AfterSchool Association. 


\section{Employee Churn}

separation from a workplace, whether voluntary or involuntary (Bureau of Labor Statistics [BLS], n.d.a). While Abbasi and Hollman (2000) identify market realities influencing employee churn, including recent economic downturn that yielded a highly mobile workforce, turnover precursors that traverse industries most often involve manager deficiencies (Buckingham \& Coffman, 1999), such as failure to adapt traditional methods for a diverse workforce, inattention to personnel, non-competitive compensation, inadequate training, and discrepant performance ratings (Abbasi \& Hollman, 2000; Kwak \& Choi, 2015). Most literature on the topic treats turnover as the dependent variable, focusing on illuminating antecedents that may help organizations prevent turnover (Glebbeek \& Bax, 2004) and its high costs, which often surpass $100 \%$ of the separated employee's annual salary (Cascio, 2006).

\section{Turnover Calculations and Misassumptions}

Turnover is converted into monthly and annual percentages using a formula that divides the number of separations by the average number of employees during the measurement period multiplied by 100 (Glebbeek \& Bax, 2004; Society for Human Resource Management, n.d.). For instance, in an organization that has an average of 10 employees, three separated employees between May 1 and May 30 would yield a monthly turnover rate of 30\% (3/10 × 100). In this scenario, the remaining staff were retained, because retention refers to the number of employees in position over an entire specified period from beginning to end (Society for Human Resource Management, n.d.). Retention is calculated by taking the number of individuals who remained employed for the entire measurement period divided by the number of employees at the start of the measurement period multiplied by 100 (Society for Human Resource Management, n.d.). Thus, in this same example company with 10 employees, seven remained in position from May 1 to May 30, resulting in a 70\% employee retention rate $(7 / 10 \times 100)$.

A common misassumption is that turnover is an automatic inverse of retention, and that together, they add up to $100 \%$. In fact, if a single position sees multiple employees turn over while other positions remain filled and stable, the combined turnover and retention rates can exceed $100 \%$. Using the same example as previously, if, among the three employees who left in May, two of them were replaced a second time within the month, the total number to employees who turned over in May would equal five. Thus, the calculation would be $5 / 10 \times$ 100 , or a turnover rate of $50 \%$. This figure would co-exist with a $70 \%$ retention rate reflecting the seven who remained in position all month. 


\section{Employee Churn}

Another frequent misunderstanding is that turnover by itself cannot exceed $100 \%$. At the same company with an average of 10 employees, if 7 workers left and were replaced, and 5 of those were replaced again within the same month, the total number of departures would be 12 . This calculation would be $12 / 10 \times 100$ or a $120 \%$ turnover rate and, because 3 workers stayed in position all month, a $30 \%$ retention rate $(3 / 10 \times 100)$. In summary, retention and turnover are complementary and related figures, but not necessarily inverses of each other, nor equaling or limited to $100 \%$.

\section{Turnover in Childcare and After-School}

Childcare turnover data reaches back nearly a century, when programs began suffering high turnover in the 1930s as teachers opted for better paying jobs in defense manufacturing (Michel, 2011). Since then, research spanning public, private, and military settings has placed childcare turnover rates between $25 \%$ and $300 \%$ annually, with current averages between $30 \%$ and 40\% (Campbell, Appelbaum, Martinson, \& Martin, 2000; First Research Industry Profiles, 2015; Nitardy, 2008; Zigler, Marsland, \& Lord, 2009). These figures are $13 \%$ to $23 \%$ higher than turnover rates for all industries combined (Compensation Force, 2015; First Research Industry Profiles, 2015) and about 4 times higher than rates for elementary education counterparts (Hale-Jinks, Knopf, \& Kemple, 2006).

Labor statistics reveal childcare compensation has remained largely stagnant since 1997, while parent childcare costs have nearly doubled (Laughlin, 2013; U.S. Department of Labor as cited in Whitebook, Phillips, \& Howes, 2014). Despite an industry generating $\$ 32$ billion annually, childcare employees remain among the lowest paid workers in any sector, earning just less than parking attendants and a bit more than dishwashers (BLS, n.d.b; Campbell et al., 2000; First Research Industry Profiles, 2015; Floyd \& Phillips, 2013; Whitebook et al., 2014). Additionally, with significant increases in childcare qualifications per state regulations, more than ever is expected of childcare workers, yet with no mirror increases in compensation. The combination of these factors makes it challenging to attract and retain quality staff (Choy \& Haukka, 2010; Cole, 2011; First Research Industry Profiles, 2015).

Data specific to childcare's after-school sub-industry is limited, but what is available echoes high turnover trends. In a Massachusetts statewide study, Dennehy and Noam (2005) established a $35 \%$ after-school staff turnover rate and an average organizational tenure of 2.8 years. A 2006 study by the National AfterSchool Association (NAA) found an environment of substantial 


\section{Employee Churn}

turnover intent, where $60 \%$ of all part-time workers planned to leave the field within 3 years, and $75 \%$ of workers under 25 years old intended to be in the field less than 3 years. Primary reasons for planned departure included desire for higher compensation outside the industry and life changes. A more recent after-school workforce study (NAA, 2017) suggested improvement in these areas; however, this study included an over-representation of salaried, higher-level participants who may not accurately reflect the hourly, part-time site staff who make up the bulk of the industry.

\section{Importance of Evaluation and Impact on Key Stakeholders}

The problem of after-school employee turnover is important to solve due to its multi-layered negative impact on key stakeholders.

- For children: Staff turnover negatively impacts quality care, cognitive development, emotional attachment, security, and long-term mental wellbeing (Campbell et al., 2000; Hale-Jinks et al., 2006; Michel, 2011; Nitardy, 2008; Whitebook et al., 2014; Zigler et al., 2009).

- For providers: Organizational viability depends upon healthy return on investment (ROI), which is jeopardized by turnover due to the costs and operational distraction of recruiting, hiring, and training replacements, as well as diminished quality, productivity, and relationships (Abbasi \& Hollman, 2000; Alkahtani, 2015; Glebbeek \& Bax, 2004; Gong, 2012; Hale-Jinks et al., 2006; Lee \& Mitchell, 2013; Nitardy, 2008).

- For families: Financial efficiency by childcare organizations is of particular importance, as poor ROI drives parent-paid tuition upward, directly impacting family participation, if not closing doors altogether (Afterschool Alliance [AA], 2015; Child Care Aware, 2015).

- For the workforce and society: After-school programs have been linked to parent job productivity and stability (AA, 2014; Employee Assistance Professionals Association, 2007; Weitzman, Mijanovich, Silver, \& Brazill, 2008). Lack of after-school program enrollment interferes with parent job performance, costing organizations an estimated $\$ 50$ to $\$ 300$ billion annually in lost productivity (Employee Assistance Professionals Association, 2007). 


\section{Organization and Purpose of the Study}

\section{Organization of Focus}

Kids' Club Incorporated [KCI] (a pseudonym) is a national student enrichment and childcare provider serving over 30,000 preschool to eighth grade children across the United States in hundreds of school-based programs. Akin to childcare trends, $\mathrm{KCI}$ has experienced high turnover among field employees who serve as frontline program staff. These program staff include program managers, who direct individual programs, and educators, who work in programs. Program staff make up $90 \%$ of KCI employees and are predominantly part-time workers, young adults with second jobs, and college students working towards degrees related to childcare or education.

\section{Turnover Improvement Goal}

As a rapidly growing organization, Kids' Club Incorporated seeks market durability and longterm mission fulfillment. Because field staff-related expenses (recruitment, onboarding, training, salaries) are KCI's greatest expenditures, improving field employee turnover is integral to organizational endurance. For the 2015-16 school year, KCI's field employee turnover rate was $54 \%$ for all field staff combined. From this figure, KCI leaders discounted employees who worked less than a total of 10 hours for the organization from turnover calculations to remove those who did not complete training. This yielded a 37\% turnover rate, from which an organizational improvement goal was set to reduce turnover to $30 \%$ for program managers and $35 \%$ for educators by spring 2017.

\section{Stakeholder Group for the Study}

Area managers (AMs), who oversee multiple school-based program locations, were selected as the focus for this study because they act as the bridge between KCI's central office, where retention policies, procedures, and resources are established, and the field, where the challenge of turnover exists. AMs also have the closest, most frequent contact with frontline staff and thus possessed the most significant potential for impacting goal achievement. 


\section{Employee Churn}

\section{Purpose of the Project and Questions}

The purpose of the study was to evaluate KCI AMs' knowledge, skills, motivation, and organizational influences related to achieving the organizational goal of improving upon a $37 \%$ employee turnover rate. The following questions guided this study:

1. In school year 2016-17, what is the gap between KCI's field employee turnover and the organizational goal of improving upon a $37 \%$ overall turnover rate to a $30 \%$ turnover rate for program managers and a 35\% turnover rate for educators by Spring 2017?

2. What are KCI AMs' knowledge, skills, motivation, and organizational influences related to achieving the turnover improvement goal?

3. What are the recommended solutions to close the knowledge, skills, motivation, and organizational gaps with regard to employee turnover at $\mathrm{KCI}$ ?

\section{General and Integrated Conceptual Frameworks}

Clark and Estes' (2008) gap analysis was utilized as the general conceptual framework for this study to explore possible causes of and solutions for employee turnover through AM knowledge and skills, motivation, and organizational factors. Figure 1 depicts a customized framework integrating gap analysis with learning and motivation theory, turnover literature across childcare and all industries, and organizational cultural models and settings (seen and unseen workplace influences) (Gallimore \& Goldenberg, 2001; Schneider, Brief, \& Guzzo, 1996). Figure 1 also represents how all influences converge with AMs to impact goal attainment and how turnover implications for key stakeholders act as both the impetus for focus and the consequence of goal attainment. 
Figure 1. Integrated Conceptual Framework for the Study

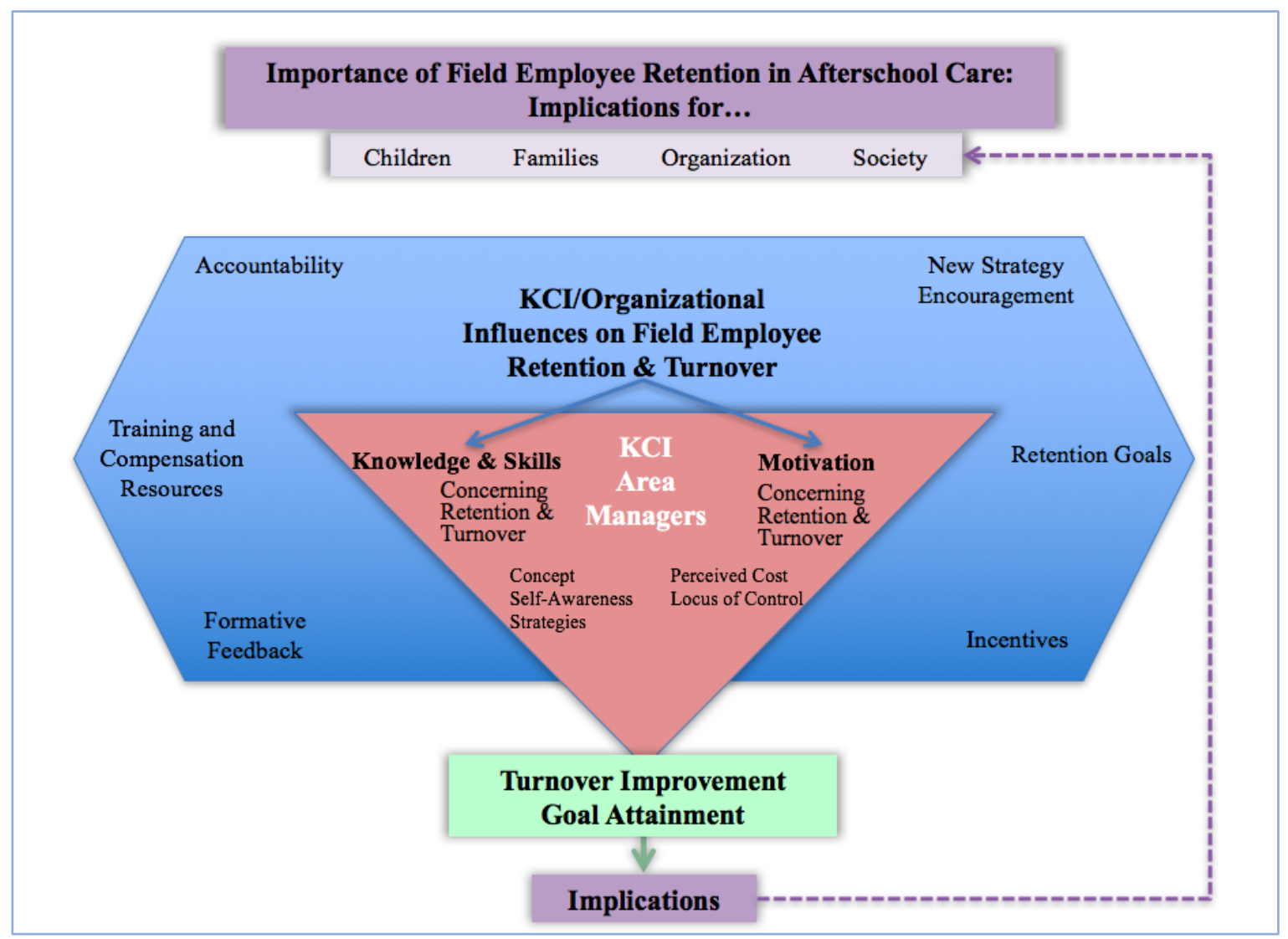

\section{Data Collection Methods and Instrumentation}

The methodological framework for the study was a convergent parallel mixed methods case study utilizing four data collection methods:

- Survey: A cross-sectional online survey of 24 closed-ended multiple choice items; census sample $(n=18)$.

- Interviews: One-on-one interviews using standardized, open-ended questions and follow-ups with a representative sample of new and veteran AMs managing new and returning programs $(n=6)$.

- Observations: In-person attendance at 6 weeks of AM team meetings with their supervisor.

- Historical document analysis: Review of 4 years of KCI turnover reports and current retention and turnover goals. 


\section{Employee Churn}

\section{Data Analysis}

Data analysis occurred in five phases:

1. KCI's employee retention and turnover rates were calculated manually.

2. Descriptive statistics were applied to quantitative survey data.

3. Open, axial, and selective coding (Merriam \& Tisdell, 2016) were applied to qualitative data from interview transcripts and observation field notes.

4. Overarching themes were established through fusion of survey, interview, and observation results.

5. Syntheses were integrated into conclusions that embodied the conceptual framework.

\section{Results and Findings}

\section{Research Question \#1: Turnover Goal Achievement}

Here are the major findings which answer the first research question about turnover goal achievement:

\section{Turnover rose, but it was unclear why.}

KCI did not meet its turnover improvement goal; in fact, turnover rose $8 \%$ in $2016-17$ to $62 \%$. Program manager turnover was 39\% compared to the goal of 30\%, while educators had $58 \%$ turnover compared to the $35 \%$ goal. Turnover was $87 \%$ voluntary and involved part-time staff $97 \%$ of the time. Reasons for turnover could not be analyzed due to limited separation coding options offered to AMs and inconsistent input by individual managers.

\section{High turnover co-occurred with high retention.}

Despite $62 \%$ turnover, retention reports indicated $74 \%$ of field employees remained in position over the same school year. As explained earlier, turnover and retention are complementary but not necessarily inverse figures, nor limited to $100 \%$ total. Thus, it is possible for both to be high.

\section{The high turnover rate was caused by repeated churn in one third of roles.}

To compare the portions of KCI's population that were stable versus unstable, retention and turnover figures needed to be weighed against the average number of employees for the entire school year. Deducting employees in programs that opened or closed mid-year, the new figure 


\section{Employee Churn}

was 356. As seen in Figure 2, 226 (63\%) of field roles remained stable, while 166 (37\%) repeatedly turned over. Hence, the high turnover rate of $62 \%$ was found to be confined to about one third of roles.

Figure 2. Stable Versus Unstable Field Employee Population, 2016-17 School Year

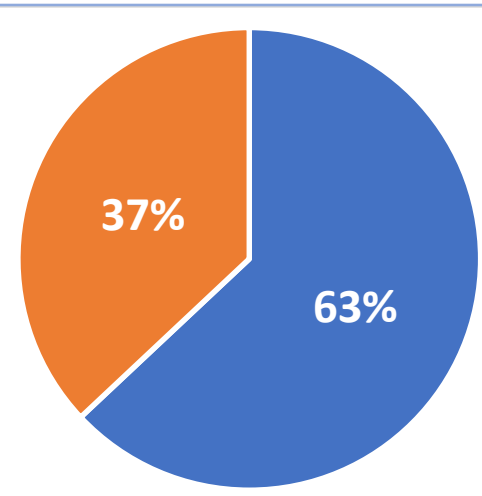

- Stable population retained over school year (226 of 356 avg. employees*)

n Churning population responsible for 62\% turnover (166 of 356 avg. employees*)

Note. The average number of employees reflects only programs that remained active throughout the whole school year. It does not include those working in programs that opened or closed mid-school-year.

\section{Research Question \#2: Retention Influences}

Here are the major findings that answer the second research question regarding managers' knowledge, skills, motivation, and organizational influences around turnover:

Managers know what turnover is and its negative consequences, including for themselves, but they do not openly ask for help.

Area managers had an accurate conceptual understanding of turnover and its negative impact, unanimously identifying consequences for children, almost unanimously for families and KCI, and less frequently for potential parents, employees, partners, and other groups shown in Figure 3. Without prompting, AMs frequently referred to the negative effects turnover has on them. Interviewees reported experiencing time pressure to fill short notice vacancies, being in "crisis mode" when unable to cover shortages, struggling with their own morale to continually hire replacements, and emotional responses to departures ranging from sadness and helplessness to frustration, anger, and numbness. The intense impact on AMs was also observed in team meetings, where AMs reported first and foremost about staffing holes and juggling job duties to fill vacancies themselves while simultaneously conducting hiring. 
Despite the significant challenge of turnover for managers, they did not openly ask for help from their supervisors or peers. Instead, AMs were observed incongruently laughing or speaking in a cheery tone about significant hiring needs and having to substitute for absent staff in programs. Some AMs missed team meetings or had to call in from another location due to subbing. At no time in team meetings were AMs observed openly or congruently discussing the pain points of turnover nor strategizing solutions.

\section{Figure 3. Typicality of Perceived Turnover Consequences for Various Populations} (Survey and Interview Results, Prompted and Non-Prompted Responses Combined)

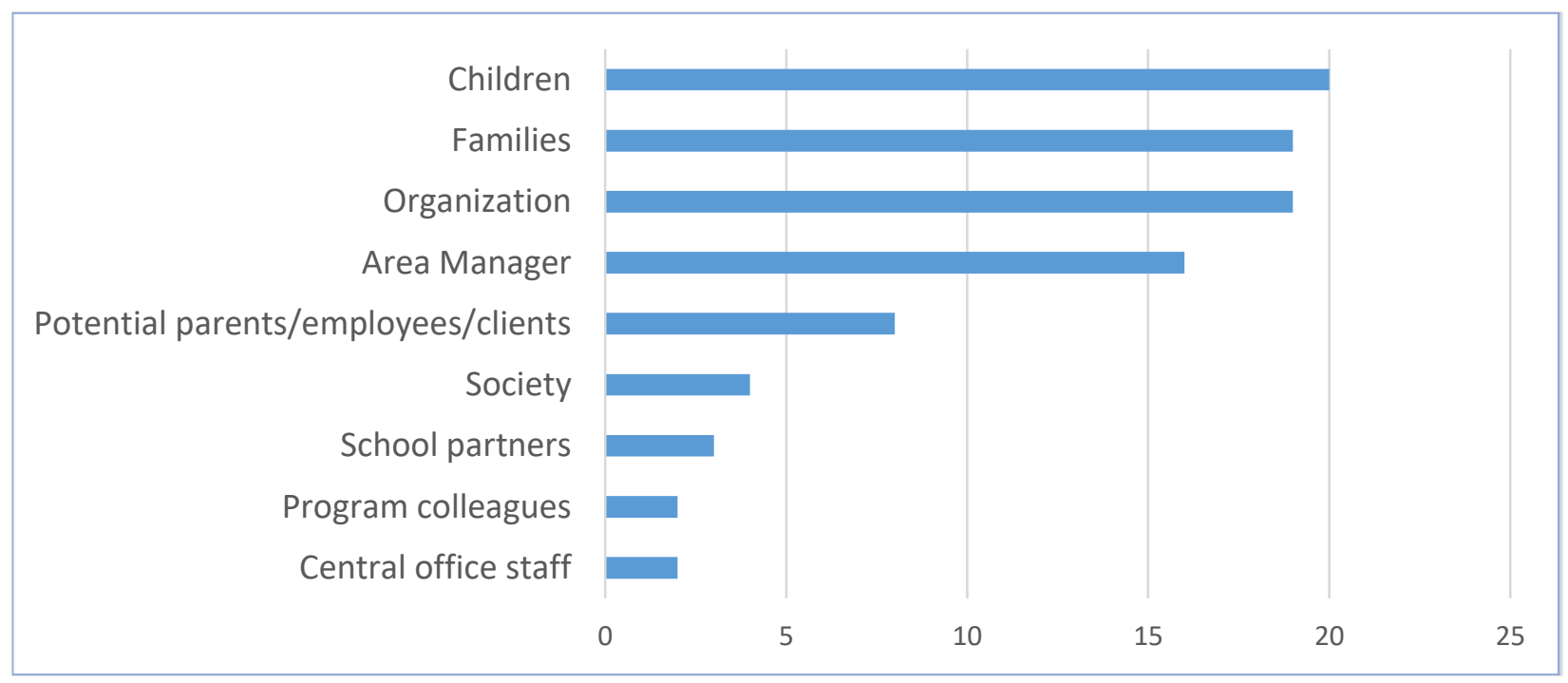

Managers see causes of turnover, but not themselves among them.

While AMs viewed managers as causal to turnover, they did not apply this rule to themselves. As seen in Figure 4, while management was the top issue when considering other managers' teams, there was no acknowledgement of management as an issue when reporting on their own team's separations. Combining surveys and interviews in Figure 5, management issues were frequently stated when AMs considered turnover in general but only once when thinking about their own team's churn. In fact, five of the six turnover causes having to do with management received zero responses when AMs reflected on their own teams, while the topranked answers largely reflected things outside AMs' purview (schedule, limited hours, resuming education, career change, pay, benefits). This was consistent with observations of AM team meetings, where the only employee turnover causes mentioned were external to the AM. 
Figure 4. Typicality of Reported Turnover Causes for All Industries Versus Area Managers' Own Team (Interview Results, Responses Not Prompted)

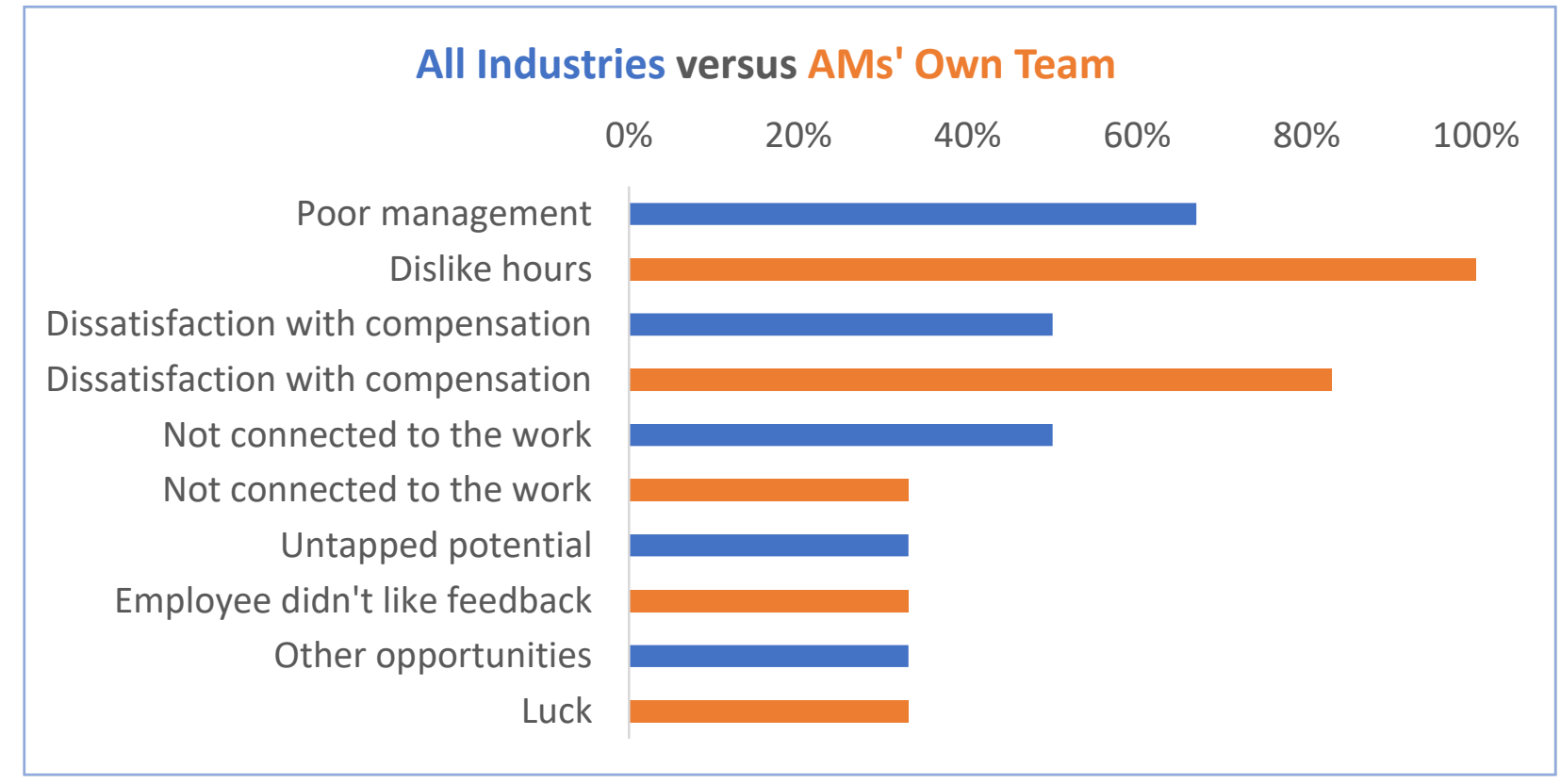

Figure 5. Frequency of Area Manager Selection of Management Issues as a Top Cause for Employee Turnover: Interview and Survey Results Combined

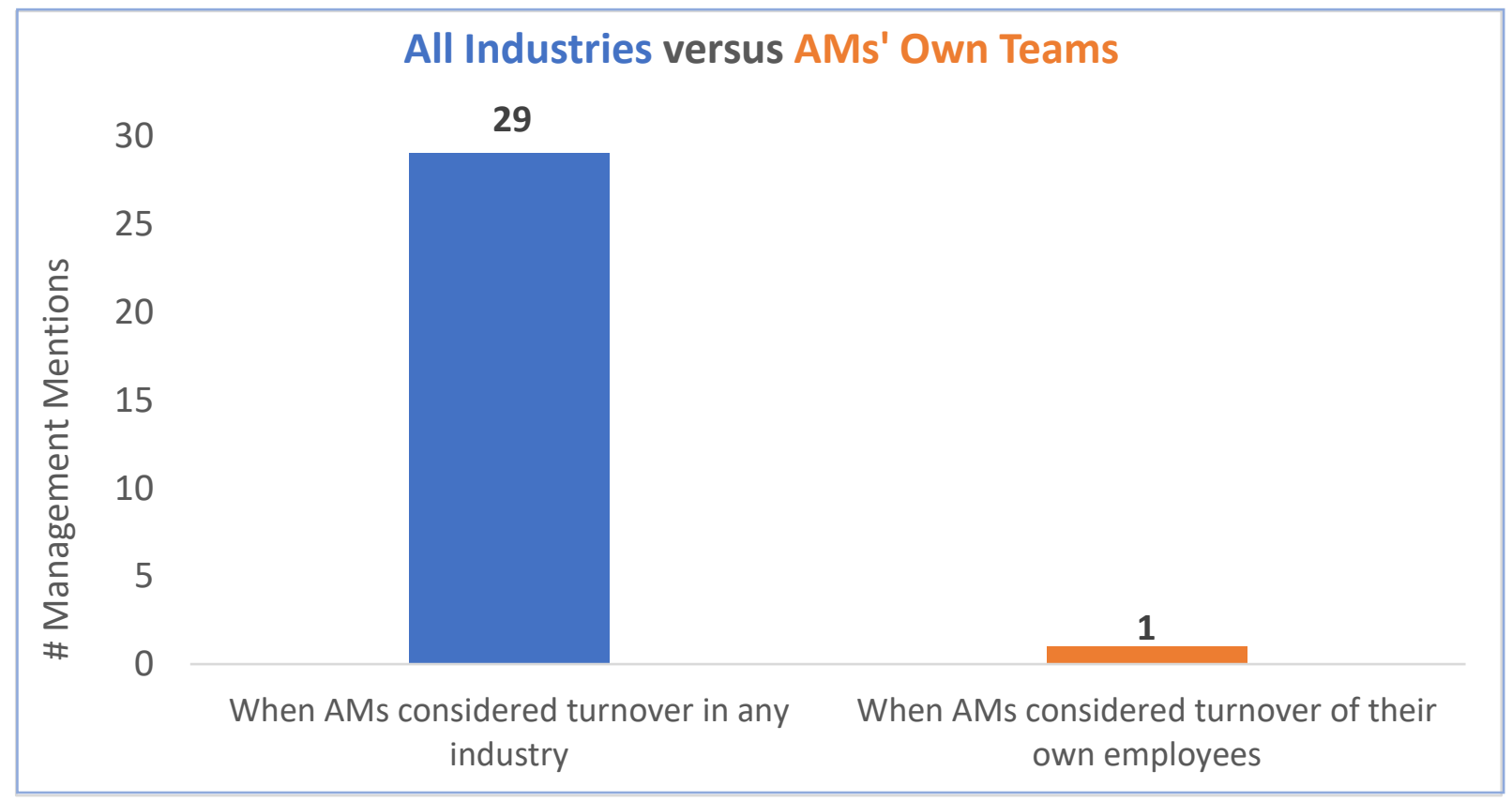




\section{Employee Churn}

Area managers' metacognitive knowledge and practices may be limited.

When inquiring about post-turnover reflection to gain insight into employee departures, AMs lacked understanding of what constitutes reflection. Additionally, in this and many other areas of inquiry, discrepancies were noted between survey responses and what was reported in interviews and observed in meetings, such as is noted throughout Figure 6. Generally, AMs were more positive on anonymous surveys and less positive during in-person interviews and observed team meetings. Veteran AMs often had a higher rate of disagreement with positive survey statements and a more negative outlook in interviews. Regardless of tenure, interviewees were often unable to back up positive claims with concrete evidence. For example, while $89 \%$ of survey respondents "agreed/strongly agreed" that they took time to reflect to gain insight on employee separations, only $50 \%$ of interviewees indicated such activity, and fewer could articulate concrete examples of reflective activities. In fact, the importance of the AM role in retention was not observed in team meetings, and interview citations referenced in Figure 6, Item 5, referred to self-imposed expectations only. No team meeting agenda indicated addressing turnover issues or retention strategies, nor did meetings observed include reflective conversations or directions to reflect outside meetings despite nearly all AMs voicing staffing gaps in team meetings and individual interviews.

\section{Managers use retention strategies learned primarily from prior experience and outside the} organization.

Area managers' knowledge of retention strategies and how to apply them appeared linked to position tenure and information from outside KCI. While most AMs reported knowing how to apply some retention strategies, as seen in Figure 6, Item 4, this was true more so for veterans, who primarily learned strategies from prior work or self-study. In team meetings observed, retention strategies were rarely mentioned. Instead, AMs repeatedly reported staffing holes without organization-led discussion around strategies for overcoming the cycle of vacancies.

\section{Managers see benefits of retention efforts as outweighing costs, but . . .}

In this study, one method of examining motivation was to compare effort to benefits as perceived cost, the part of Expectancy Value Theory that involves the value a person assigns to a task (Eccles et al. as cited in Eccles, 2006). All AMs expressed belief that the effort they exert to retain employees is worth it, as seen in Figure 6, Items 1 and 2. However, this finding stood in direct contrast to the next finding of significant external attribution for turnover. 


\section{Figure 6. Survey Results}

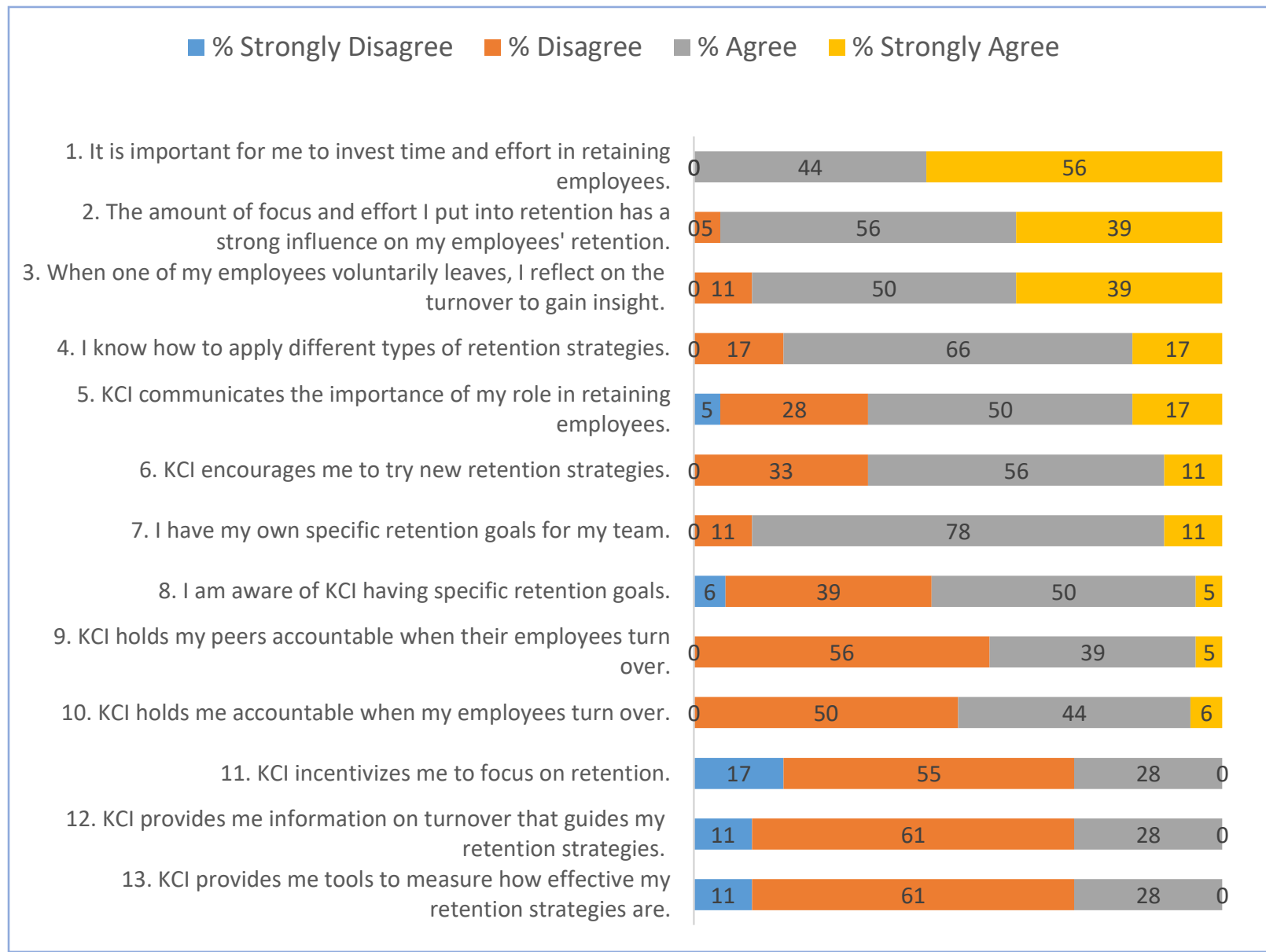

Managers view turnover as largely out of their control.

Motivation was further explored in relation to Weiner's (1985) attribution theory model, where event causation is viewed in part as having internal or external locus of control to the individual (Anderman \& Anderman, 2006; Weiner, 1985). Internal locus of control fuels effort both in cases of success and failure, while external locus of control is associated with hopelessness (Anderman \& Anderman, 2006; Rueda, 2011; Weiner, 1985). Just as AMs nearly unanimously cited external causes for their own team's turnover, $100 \%$ of their turnover references in team meetings also cited external causes (relocation, illness, taking a full-time job elsewhere). Similarly, in interviews illustrated in Figure 7, typicality of external causes for turnover outnumbered internal causes 57 to 12 . However, Figure 6, Item 2 reveals another reporting discrepancy, where more positive reports of internal control over turnover were made on the survey compared to interviews and observed meetings. 
Figure 7: Attribution: Typicality of Internal versus External Locus of Control for Turnover (Interview Results)

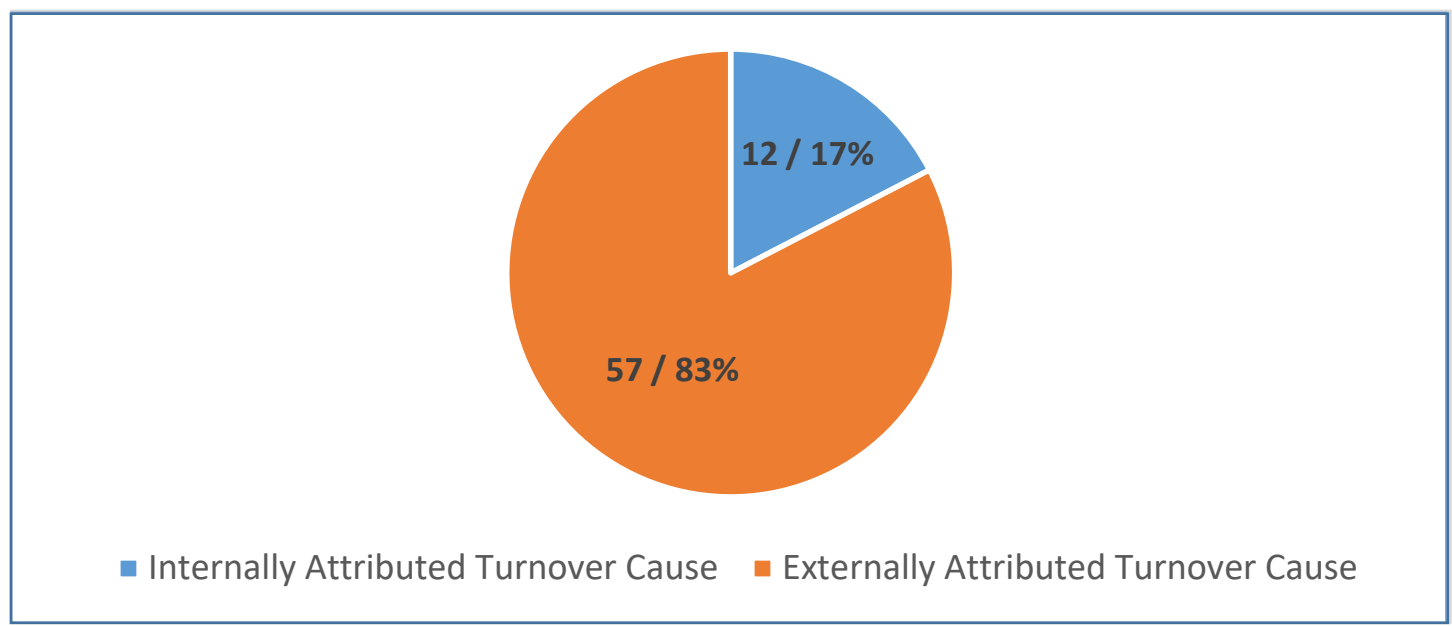

Organizational accountability for turnover is lacking.

Area managers' sense of responsibility for turnover was not necessarily driven by concrete organizational accountability practices. Despite AMs citing themselves as responsible for turnover, actual accountability was rated lower on surveys (see Figure 6, Items 9 and 10), reported even less frequently in interviews, and absent in observed team meetings. While nearly half of AMs surveyed reported being held accountable for turnover by $\mathrm{KCI}$, no AMs interviewed could point specifically to how they or any peer was held responsible.

Peers are a primary source of support for trying new retention strategies.

Area managers' reports regarding encouragement to try new retention strategies were inconsistent. In surveys, two thirds of AMs said KCI encourages them to try new retention strategies, while one third said they are not encouraged (see Figure 6, Item 6). In interviews, however, the inverse was true. AMs most often mentioned their peers as their primary source of encouragement for trying new strategies, a supportive dynamic that was validated in team meetings in comments made around operational problem-solving.

\section{Concrete retention goals are lacking.}

Though many AMs reported knowing the organization's retention goals and having their own, this was not supported by evidence. As seen in Figure 6, Item 8, 55\% agreed to knowing KCI has specific employee retention goals, while $45 \%$ did not. (Note: goals had ever been shared with managers.) When asked on the survey if they had their own retention goals, AMs resoundingly agreed (89\%), as Figure 6, Item 7 depicts; however, in interviews, two thirds of 


\section{Employee Churn}

AMs were unable to articulate any pre-set goals, and the one third who did seemed to be generating them on the spot.

\section{Retention is not organizationally incentivized but still has an internal motivating force.} Most AMs (73\%) did not see $\mathrm{KCI}$ as providing incentives for them to focus on retention, as shown in Figure 6, Item 11. Veterans far more strongly expressed a lack of incentives (90\%) compared to new AMs (50\%). Managers spoke most often about retention benefits in terms of avoiding personal suffering, such as having to personally fill staffing holes or hire and train new people, and therefore being unable to attend to other duties.

\section{Turnover and retention data and feedback are not getting to managers.}

When it comes to actionable information on employee retention and turnover, AMs largely indicated a lack of formative feedback. Most AMs (72\%) disagreed that KCI provides information on employee turnover or strategy efficacy that guides their retention approach, as shown in Figure 6, Items 12 and 13. As with other items, veteran AMs far more strongly disagreed (90\%) compared to new AMs (50\%). In interviews, $100 \%$ of AMs indicated a complete lack of turnover feedback provided by KCI, as well as an absence of tools to measure retention strategy efficacy.

\section{Summary and Organizational Implications}

Four major themes emerged across results, each presenting the possibility for perpetuating after-school field employee turnover and placing organizational viability at risk:

\section{Theme 1: Limited Knowledge and Insight Generation}

While AMs have considerable direct experience with employee turnover, there is a lack of formative turnover data provided by $\mathrm{KCI}$ and an absence of guided reflective practices to gain insight and make improvements. Additionally, AM time to practice reflection appears to be held hostage by managers' ongoing crises of covering their own vacancies. This causes AMs to largely draw upon prior and outside experience for retention strategies, which may or may not be applicable or effective. The lack of actionable data and essential insights into turnover could be fueling cyclical continuation and/or exacerbation of turnover. 


\section{Employee Churn}

\section{Theme 2: Lack of Organizational Supports and Accountability}

Area managers clearly hold a belief in the importance of and responsibility for turnover; however, this belief is held almost solely internally and is not supported by concrete organizational practices. Retention efforts appear outside the context of organizational goals, incentives, feedback, or accountability. AMs tend to put forth effort without specific direction or confidence; in other words, they are "throwing retention strategies at the wall and seeing what sticks." With no organizational framework empowering AMs around retention, nor specific consequences for churn, when it comes to turnover, AMs may remain intrinsically earnest but organizationally aimless.

\section{Theme 3: Inconsistent Positivity and Learned Helplessness}

Disparate levels of positivity in varied study settings and between new and veteran respondents suggest different experiences based upon manager tenure and/or an unstated cultural expectation of tolerating high turnover. AMs were consistently more positive on surveys than they were in interviews or in what was observed in team meetings. This may indicate a desire to see things more positively in an anonymous setting, but an inability to sustain that positivity when evidence was required in in-person exchanges. The consistently greater negativity expressed behind closed interview doors may also imply an unstated organizational cultural model that AMs should not openly voice their struggles with turnover. Similarly, consistently greater veteran negativity could be the result of learned helplessness (Overmier \& Molet, 2013) that developed over time with the role and/or industry.

\section{Theme 4: Lack of Control and Ownership}

Area managers overwhelmingly saw external causes for their own team's turnover in direct contrast with their perceptions of other managers and literature. And yet, managers saw their influence when it came to retention success. This appears to parallel Weiner's (1985) hedonic bias, or the tendency to attribute success internally but failure externally. In other words, AMs viewed their own positive influence on retention up until the point of turnover, at which time the onus shifted to external factors. Furthermore, the heavy external locus of control for turnover coupled with less agreement among veterans about retention influence reinforces the idea that learned helplessness develops over time and experience. External and stable attributions are predictive of lower motivation (Weiner, 1985), which is connected to persistence and mental effort (Clark \& Estes, 2008). Therefore, AMs' lack of engagement with their own influence could be undermining individual and collective retention efforts and thwarting achievement of the organizational retention goal. 


\section{Employee Churn}

\section{Recommended Solutions}

To answer the third research question about solutions, context-specific recommendations were developed, followed by an integrated implementation and evaluation plan that incorporated the New World Kirkpatrick Model (Kirkpatrick \& Kirkpatrick, 2016). Shown in Table 1, recommendations were grounded in cross-industry literature on retention methods, $\mathrm{KCI}$ organizational culture and resources, and areas of vulnerability revealed by the study. Solutions were implemented with KCI AMs beginning mid-fall 2017.

\section{Table 1. Context-Specific Recommended and Implemented Solutions}

\begin{tabular}{|c|c|c|}
\hline $\begin{array}{c}\text { Knowledge and skills } \\
\text { solutions }\end{array}$ & Motivation solutions & $\begin{array}{c}\text { Organizational resource } \\
\text { solutions }\end{array}$ \\
\hline $\begin{array}{l}\text { - Provide area managers } \\
\text { (AMs) actionable retention } \\
\text { and turnover data. } \\
\text { - Provide AMs training on and } \\
\text { time to practice } \\
\text { metacognition to gain insight } \\
\text { into their own team's } \\
\text { retention and turnover. } \\
\text { - Provide AMs information and } \\
\text { job aids for effective } \\
\text { employee support strategies, } \\
\text { as well as time to share } \\
\text { success stories among } \\
\text { peers. }\end{array}$ & $\begin{array}{l}\text { - Retrain AMs on attribution for } \\
\text { employee turnover to } \\
\text { increase internal locus of } \\
\text { control. } \\
\text { - Challenge AMs when external } \\
\text { locus of control is expressed } \\
\text { as the primary reason for } \\
\text { employee turnover. }\end{array}$ & $\begin{array}{l}\text { - Develop a culture of } \\
\text { accountability for employee } \\
\text { retention and turnover, as } \\
\text { well as a concrete } \\
\text { accountability framework for } \\
\text { AMs. } \\
\text { - Regularly encourage AMs to } \\
\text { try new retention strategies. } \\
\text { - Share organizational retention } \\
\text { goals with AMs, and assist } \\
\text { AMs in setting related } \\
\text { individual goals. } \\
\text { - Provide AMs formative } \\
\text { feedback on retention efforts } \\
\text { to measure efficacy and } \\
\text { inform needed adjustments. } \\
\text { - Tie organizational recognition } \\
\text { and rewards to AM retention } \\
\text { goal attainment. }\end{array}$ \\
\hline
\end{tabular}




\section{Post-Study Outcomes: Impact of Solutions Implemented}

After the introduction of solutions at KCI in fall 2017, a second survey of AMs was conducted in January 2018 ( 3 months into solutions implementation and 1 year after the initial survey). The follow-up inquiry mirrored the original survey population, questions, and format. Interviews and observations were not repeated. Retention and turnover reports for the school year following the study were also reviewed. Results indicated significant improvements across all areas of manager mindset, as well as with retention and turnover rates and stability of field employee roles.

\section{Significant Improvements in Manager Mindset}

Follow-up survey results showed significant positive shifts in AMs' turnover knowledge, skills, motivation, and perception of organizational resources. Depicted in Tables 2, 3, and 4, AMs' responses demonstrated improvement in 16 of 17 mindset areas, and $90 \%$ or better agreement in 12 of 17 areas measured.

Table 2. Knowledge of Retention and Turnover: 1-Year Follow-Up Survey

\begin{tabular}{|l|l|c|}
\hline \multirow{2}{*}{$\begin{array}{c}\text { Knowledge } \\
\text { type }\end{array}$} & \multicolumn{1}{c|}{ Manager knowledge } & $\begin{array}{c}\text { New "agree" } \\
\text { and "strongly } \\
\text { agree" total }\end{array}$ \\
\hline \multirow{2}{*}{ Declarative } & Turnover consequences for children & $100 \%$ \\
\cline { 2 - 3 } & Turnover consequences for families & $100 \%$ \\
\cline { 2 - 3 } & Turnover consequences for KCI & $100 \%$ \\
\hline Metacognitive & Turnover consequences for society & $91 \%$ \\
\hline Procedural & Reflection on turnover of employees & $100 \%$ \\
\hline
\end{tabular}


Table 3. Motivation to Address Retention and Turnover: 1-Year Follow-Up Survey

\begin{tabular}{|l|l|c|}
\hline \multicolumn{1}{|c|}{ Motivation type } & \multicolumn{1}{|c|}{ Manager belief } & \multicolumn{1}{|c|}{$\begin{array}{c}\text { New "agree" plus } \\
\text { "strongly agree" total }\end{array}$} \\
\hline Perceived Cost (Expectancy Value Theory) & $\begin{array}{l}\text { My retention efforts are } \\
\text { important. }\end{array}$ & $100 \%$ \\
\hline Locus of Control (Attribution Theory) & $\begin{array}{l}\text { My retention efforts make a } \\
\text { difference. }\end{array}$ & $95 \%$ \\
\hline
\end{tabular}

Table 4. Perception of Organizational Resources for Retention and Turnover: 1-Year Follow-Up Survey

\begin{tabular}{|l|l|c|}
\hline \multirow{2}{*}{$\begin{array}{c}\text { Organizational } \\
\text { support area }\end{array}$} & \multicolumn{1}{|c|}{ Manager perception } & \multicolumn{1}{|c|}{$\begin{array}{c}\text { New "agree" plus } \\
\text { "strongly agree" total }\end{array}$} \\
\hline \multirow{2}{*}{ Accountability } & $\begin{array}{l}\text { Organization communicates importance of manager } \\
\text { role in retention }\end{array}$ & Organization holds manager accountable for turnover \\
\cline { 2 - 3 } & $\begin{array}{l}\text { Organization holds manager peers accountable for } \\
\text { turnover }\end{array}$ & $76 \%$ \\
\hline \multirow{2}{*}{ Encouragement } & $\begin{array}{l}\text { Organization encourages manager to try new retention } \\
\text { strategies }\end{array}$ & $71 \%$ \\
\hline \multirow{2}{*}{ Goals } & Manager knows organization's retention goals & $95 \%$ \\
\cline { 2 - 3 } & Manager has own retention goals & $100 \%$ \\
\hline Incentives & Organization incentivizes manager to focus on retention & $95 \%$ \\
\hline \multirow{2}{*}{$\begin{array}{l}\text { Formative } \\
\text { Feedback }\end{array}$} & $\begin{array}{l}\text { Organization provides manager information on turnover } \\
\text { that guides retention strategies }\end{array}$ & $48 \%$ \\
\cline { 2 - 3 } & $\begin{array}{l}\text { Organization provides manager tools to measure } \\
\text { retention strategy efficacy }\end{array}$ & $81 \%$ \\
\hline
\end{tabular}




\section{Significant Improvement in Employee Turnover}

Following implementation of solutions beginning in fall 2017, end-of-school-year retention and turnover reports for 2017-18 showed turnover dropped $22 \%$ year-over-year to $40 \%$, while high retention (75\%) was maintained, as seen in Table 5.

Table 5. Retention and Turnover Rates Comparison: Year of Study to Post-Solutions Implementation

\begin{tabular}{|c|c|c|c|}
\hline Indicator & $\begin{array}{c}\text { School Year 2016-17 } \\
\text { rate }\end{array}$ & $\begin{array}{c}\text { School Year 2017-18 } \\
\text { rate }\end{array}$ & Change \\
\hline Turnover & $62 \%$ & $40 \%$ & $-22 \%$ \\
\hline Retention & $74 \%$ & $75 \%$ & $+1 \%$ \\
\hline
\end{tabular}

Note. Implementation of solutions began in fall of 2017.

\section{Improvement in Role Stability}

Analysis also revealed additional progress occurred in the ratio of stable versus unstable employee roles. As Figure 8 shows, stable roles rose by $8 \%$, from $67 \%$ in the year of study to $75 \%$ one year later, while unstable roles, where repeated turnover occurred, improved by $11 \%$, dropping from $37 \%$ in the year of study to $25 \%$ one year later.

Figure 8. Stable Versus Unstable Field Employee Population: 1-Year Follow-Up Analysis

\section{Repeated churn \\ in this portion of \\ roles (11\% \\ decrease from \\ prior year)}

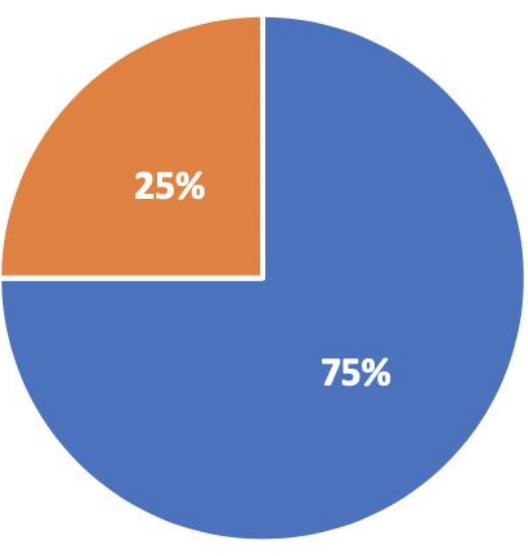

Stability in this portion of roles (8\% increase from prior year)

- Stable population retained over school year

- Churning population responsible for $44 \%$ turnover rate 


\section{Employee Churn}

\section{Organizational Savings}

The result of implemented solutions translated to an average of eight fewer employee replacements per AM in 2017-18, over 200 after-school employees saved, and over $\$ 200,000$ in onboarding savings. Other unmeasured positive impact, such as preserved positive child outcomes, sustained parent/client relationships, and retained organizational reputation, are inferred based upon prior cited literature.

\section{Limitations of the Study}

In this study, limitations included a small manager population, varied manager vocabulary, inability to observe reflection on turnover or discussion of retention strategies in other settings (such as one-on-ones with a regional director or independent study), no prior national afterschool turnover studies or previously established context-specific instruments to draw upon, and turnover reports that, not having been developed for research, at times lacked meaningful insights.

\section{Recommendations}

\section{Recommendations for Future Study in the After-School Industry}

There has been little information historically about after-school industry turnover rates, with a few state studies as the exception. National workforce surveys conducted in recent decades do not provide reliable reflections of after-school industry retention, having experienced an overrepresentation of participants holding management or higher positions. This resulted in workforce data favoring full-time, more highly educated and compensated staff who work in the profession for longer periods of time and at greater levels of satisfaction compared to the far more common program staff who make up the bulk of the industry. Thus, the after-school profession would benefit from more study related to employee retention and turnover at the program employee level in terms of job and industry tenure, reasons for and prevalence of turnover, and responsiveness to retention interventions. Additional opportunities exist for more robust exploration of turnover trends over time and geographic areas that would allow local after-school organizations and regional networks to better understand their turnover reality relative to the industry, and subsequently, to inform goal-setting and justify focus and resource allocation for solutions. Lastly, given the pervasive challenge to providers, the after-school industry would benefit from focused and regular national dialog on retention and turnover, with preventable causes and generalizable solutions central to idea sharing. 


\section{Recommendations for Study by After-School Care Organizations}

For organizations or networks wishing to conduct formal, in-depth study of their own turnover challenges to develop context-specific solutions, it is recommended they do so in a mixed methods approach, gathering qualitative and quantitative insights similar to this study to glean the most complete understanding of the barriers in mindset and perceived resources in order to point to the most potentially effective solutions. For those wanting to replicate or adapt this study, the full dissertation and Appendices containing research- and literature-grounded survey, interview, and observation instrumentation and protocols can be found at https://pqdtopen.proquest.com/doc/2058668920.html?FMT=ABS.

After-school providers may also simulate less formal self-inquiry into retention and turnover using the following recommended steps and questions:

Step 1. Begin by assessing the organization's actionable retention and turnover information.

a. What retention and turnover data exist, if any? In what form?

b. How recent is it? Is it valid and reliable?

c. Who in the organization has eyes on it? How often?

d. How is the data used, if at all, to drive improvement in retention and/or turnover? Step 2. Determine what is being done to retain employees by different managers across the organization.

a. What established effective retention strategies are managers using? Examples are

i. investigating and analyzing departures

ii. employee-supervisor relationship-building

iii. employee recognition

- advancement opportunities and/or career pathing

- incentivizing retention with training, advancement, or financial means

- "going for the save" (negotiating with an employee who has indicated plans to depart)

- competitive compensation and/or benefits restructuring

b. How do managers and the organization know which strategies are effective? Can they justify their choice of interventions?

c. How consistent are managers with retention efforts?

i. How often and for how long do they apply different strategies?

ii. How does the organization know managers are actually using retention strategies as often as they say they are? 


\section{Employee Churn}

iii. What do managers say gets in the way of focusing on retention?

Step 3. Train supervisors to lead insight-generating dialog with and among managers about retention and turnover.

a. How do supervisors create an environment where managers can talk openly about challenges with retention and turnover?

b. How do supervisors challenge managers' barriers to insight (e.g. lack of awareness, transparency, accountability, etc.)?

Step 4. Address and retrain external attribution for turnover.

a. What retention factors in the organization are truly controllable?

b. How do supervisors challenge managers to focus on what is controllable instead of blaming the uncontrollable and remaining helpless?

c. What legitimate barriers to retention success do managers have, and how does the organization work to remove them?

Step 5. Set goals and provide regular feedback.

a. How does the organization set \& communicate turnover improvement and/or retention goals? How do managers' individual goals connect to organizational goals?

b. When/how often/with what data does the organization benchmark progress?

c. How long should a new strategy be employed before evaluating? What constitutes a timely adjustment when retention efforts do not appear to be effective?

d. How and when do managers share winning strategies?

Step 6. Encourage, incentivize, and reward managers related to retention and turnover.

a. What form of encouragement do managers want and/or need to try new retention strategies?

b. What does public recognition and/or reward of managers for retention efforts and success look and/or sound like?

Step 7. Create an accountability framework around retention and turnover.

a. How do supervisors communicate ownership of turnover with managers?

b. What does managing performance around retention \& turnover look and/or sound like?

c. What form of accountability does the organization use to hold managers responsible for achieving retention and turnover goals?

d. What consequences are there for managers who have persistent turnover?

Step 8. Determine organizational resources needed to fulfill Steps 1-7.

a. What specific support among organizational leadership is needed, and what does that support look/sound like? 


\section{Employee Churn}

b. What internal partners, external consultants, financial resources, etc. are needed?

\section{Recommended Turnover Solutions for All After-School Providers}

After-school organizations wishing to address their own turnover challenges may adapt any portion of the solutions found in Table 1 with confidence that they are grounded in broad retention and turnover research and literature, as well as demonstrated to be effective in a national after-school organization operating in diverse urban, suburban, and rural U.S. markets drawing upon minimal resources and achieving positive results. As such, the solutions in Table 1 may be fully or partly generalizable to other after-school providers independent of organizational size, structure, or geography. The degree to which self-study is conducted, whether using the formal or informal replication of inquiry described in this article under the heading, "Recommendations for Study by Afterschool Care Organizations" or another method, could proportionally increase the likelihood of determining context-specific solutions that would elevate positive impact.

\section{Conclusion}

This study sought to understand the status of after-school field employee turnover at Kids' Club Incorporated (KCI) in relation to its organizational turnover improvement goal and to use Clark and Estes' (2008) gap analysis framework to assess the knowledge, skills, motivation, and organizational influences of those who are most influential with frontline employee retention and turnover-AMs who oversee program staff. Analysis revealed high employee turnover cooccurring with high retention, with the repeated churn of about one third of KCI's roles causing the high turnover. Survey, interview, and observation results illuminated thematic gaps, including areas of limited knowledge with turnover; minimally perceived organizational supports for retention; disparate levels of positivity by manager tenure and study setting; significant external locus of control over turnover, including possible learned helplessness, and; lack of ownership and accountability for turnover. The implications of findings pointed to the risk of continued high turnover, where AMs may remain at odds with their own influence due to lack of critical knowledge, skills, motivation, and organizational resources. By implementing the recommended context-specific solutions, $\mathrm{KCI}$ began to effectively address its turnover in ways that significantly elevated manager mindset and empowerment around retention and turnover, decreased detrimental churn, and afforded increased employee stability and measurable organizational savings. 


\section{Employee Churn}

This in-depth study may be replicated or adapted by organizations using all or part of the original framework, measurement tools, and protocols. Providers may also use an informal 8step inquiry recommended to self-assess and begin to identify turnover improvement opportunities. Research- and literature-based solutions developed in this micro-organizational study may be generalized to other after-school providers to positively influence manager knowledge, skills, motivation, and organizational resources for employee retention and turnover.

\section{Original Study}

Wilkens, M. (2017). Employee churn in afterschool care: An evaluation study of manager knowledge, skills, motivation, and organizational influences on employee retention and turnover. [Doctoral dissertation, Rossier School of Education, University of Southern California, Los Angeles.] https://pqdtopen.proquest.com/doc/2058668920.html?FMT=ABS

\section{References}

Abbasi, S. M., \& Hollman, K. W. (2000). Turnover: The real bottom line. Public Personnel Management, 29(3), 333-342. https://doi.org/10.1177/009102600002900303

Afterschool Alliance. (2014). America after 3pm: Afterschool programs in demand. http://www.afterschoolalliance.org/documents/AA3PM-2014/AA3PM National Report.pdf

Afterschool Alliance. (2015). 21 $1^{\text {st }}$ century community learning centers overview. http://afterschoolalliance.org/documents/21stCCLC Overview 030515.pdf

Alkahtani, A. H. (2015). Investigating factors that influence employees' turnover intention: A review of existing empirical works. International Journal of Business and Management, 10(12), 152-166. https://doi.org/10.5539/ijbm.v10n12p152

Anderman, E., \& Anderman, L. (2006). Attributions. http://www.education.com/reference/article/attribution-theory/

Buckingham, M., \& Coffman, C. (1999). First, break all the rules: What the world's greatest managers do differently. New York, NY: Simon \& Schuster.

Bureau of Labor Statistics, U.S. Department of Labor. (n.d.b). Occupational outlook handbook, 2014-15 edition, childcare workers. http://www.bls.gov/ooh/personal-care-and-service/childcareworkers.htm

Bureau of Labor Statistics, U.S. Department of Labor. (n.d.a) Turnover [Def. 1]. http://www.bls.gov/bls/glossary.htm\#T 
Journal of Youth Development | http://jyd.pitt.edu/ | Vol. 15 Issue 1 DOI 10.5195/jyd.2020.812 Employee Churn

Campbell, N. D., Appelbaum, J. C., Martinson, K., \& Martin, E. (2000). Be all that we can be: Lessons from the military for improving our nation's child care system. Washington, DC: National Women's Law Center. http://files.eric.ed.gov/fulltext/ED441582.pdf

Cascio, W. F. (2006). Managing human resources: Productivity, quality of work life, profits (7th ed.). Burr Ridge, IL: Irwin/McGraw-Hill.

Child Care Aware. (2015). Parents and the high cost of child care. https://www.childcareaware.org/wpcontent/uploads/2016/05/Parents-and-the-High-Cost-of-Child-Care-2015-FINAL.pdf

Choy, S., \& Haukka, S. (2010). Effective employment-based training models for childcare workers. Australian Journal of Adult Learning, 50(1), 141-163.

Clark, R. E., \& Estes, F. (2008). Turning research into results: A guide to selecting the right performance solutions. Charlotte, NC: Information Age.

Cole, P. (2011). Building an afterschool workforce: Regulations and beyond. Afterschool Matters, 13, 1221. http://eric.ed.gov/?id=EJ980175

Compensation force. (2015). 2015 turnover rates by industry. http://www.compensationforce.com/2016/04/2015-turnover-rates-by-industry.html

Dennehy, J., \& Noam, G. G. (2005). Evidence for action: Strengthening after-school programs for all children and youth: The Massachusetts out-of-school time workforce. Boston, MA: Achieve Boston, an Initiative of Boston After School and Beyond.

http://www.pearweb.org/pdfs/OSTWorkforceReport.pdf

Eccles, J. (2006). Expectancy value motivational theory. http://www.education.com/reference/article/expectancy-value-motivational-theory/

Employee Assistance Professionals Association. (2007). Worries about children's after-school activities lower productivity of working parents. Journal of Employee Assistance, 37(2), 30.

First Research Industry Profiles. (2015). Child care services - quarterly update 12/7/2015. Austin, TX: Hoover's.

Floyd, L., \& Phillips, D. (2013). Child care and other support programs. Future of Children, 23(2), 79-97. https://www.jstor.org/stable/23595621

Gallimore, R., \& Goldenberg, C. (2001). Analyzing cultural models and settings to connect minority achievement and school improvement research. Educational Psychologist, 36(1), 45-56. https://doi.org/10.1207/S15326985EP3601 5

Glebbeek, A. \& Bax, E. (2004). Is high employee turnover really harmful? An empirical test using company records. The Academy of Management Journal, 47(2), 277-286.

https://doi.org/10.2307/20159578

Gong, Y. (2012). What makes people stay? The different effects of on-the-job and off-the-job embeddedness on voluntary turnover (Doctoral dissertation). Retrieved from ProQuest. (Order No. 3536387) 
Journal of Youth Development | http://jyd.pitt.edu/ | Vol. 15 Issue 1 DOI 10.5195/jyd.2020.812 Employee Churn

Hale-Jinks, C., Knopf, H., \& Kemple, K. (2006). Tackling teacher turnover in child care: Understanding causes and consequences, identifying solutions. Childhood Education, 82(4), 219-226. https://doi.org/10.1080/00094056.2006.10522826

Kirkpatrick, J. D., \& Kirkpatrick, W. K. (2016). Kirkpatrick's four levels of training evaluation. Alexandria, VA: ATD Press.

Kwak, W. J., \& Choi, S. B. (2015). Effect of rating discrepancy on turnover intention and leader-member exchange. Asia Pacific Journal of Management, 32(3), 801-824. https://doilorg/10.1007/s10490$\underline{015-9414-3}$

Laughlin, Lynda. 2013. Who's minding the kids? child care arrangements: Spring 2011 (Current Population Reports, P70-135). U.S. Census Bureau, Washington, DC.

Lee, T. W. \& Mitchell, T. R. (2003). Control turnover by understanding its causes. In E. A. Locke (Ed.), The Blackwell handbook of principles of organizational behaviour (pp. 93-107). Oxford, UK: Blackwell.

Michel, S. (2011). The history of child care in the U.S. Retrieved from http://www.Socialwelfarehistory.com/programs/child-care-the-american-history/

Merriam, S. B., \& Tisdell, E. J. (2016). Qualitative research: $A$ guide to design and implementation (4 ${ }^{\text {th }}$ ed.). San Francisco, CA: Jossey-Bass.

National AfterSchool Association. (2017). The state of afterschool quality: Promoting professionalism. Washington, DC: Author.

National AfterSchool Association. (2006, August). Understanding the afterschool workforce: Opportunities and challenges for an emerging profession. Washington, DC: Cornerstone for Kids.

Nitardy, C. (2008). The relationship between career development and intent to stay in a high turnover industry, early childhood education and care (Doctoral dissertation). Retrieved from ProQuest. (Order No. 3295695)

Overmier, J. B., \& Molet, M. (2013). Learned helplessness Oxford University Press. https://doi.org/10.1093/obo/9780199828340-0112

Rueda, R. (2011). The three dimensions of improving student performance. New York, NY: Teachers College Press.

Schneider, B., Brief, A., \& Guzzo, R. (1996). Creating a culture and climate for sustainable organizational change. Organizational Dynamics, 24(4), 7-19. https://doi.org/10.1016/S0090-2616(96)90010-8

Society for Human Resource Management. (2015). SHRM survey findings: Employee recognition programs - 2015. Author. https://www.shrm.org/hr-today/trends-and-forecasting/research-andsurveys/pages/shrm-globoforce-employee-recognition-2015.aspx

Society for Human Resource Management. (n.d.). Calculate turnover. Available from https://www.shrm.org

Weiner, B. (1985). An attributional theory of achievement motivation and emotion. Psychological Review, 92(4), 548-573. https://doi.org/10.1037//0033-295X.92.4.548 
Journal of Youth Development | http://jyd.pitt.edu/ | Vol. 15 Issue 1 DOI 10.5195/jyd.2020.812

\section{Employee Churn}

Weitzman, B. C., Mijanovich, T., Silver, D., \& Brazill, C. (2008). If you build it, will they come?: Estimating unmet demand for after-school programs in America's distressed cities. Youth \& Society, 40(1), 3-

34. https://doi.org/10.1177/0044118X08314262

Whitebook, M., Phillips, D., \& Howes, C. (2014). Worthy work, still unlivable wages: The early childhood workforce 25 years after the national child care staffing study. Berkeley: Center for the Study of Child Care Employment, University of California.

https://cscce.berkeley.edu/files/2014/ReportFINAL.pdf

Zigler, E., Marsland, K., \& Lord, H. (2009). The tragedy of child care in America. New Haven, CT: Yale University Press. 